\title{
A cross-cultural examination of the impact of social, organisational and individual factors on educational technology acceptance between British and Lebanese university students
}

\author{
Ali Tarhini, Kate Hone and Xiaohui Liu
}

Dr Ali Tarhini is a researcher within the Human Computer Interaction (HCI) group, Department of Information System and Computing, Brunel University, London, UK. His research interests include Educational Psychology, ICT in Education, human-computer interaction, cross-cultural aspects of e-learning use in higher educational institutions, user adoption and acceptance of technology. Kate Hone is a Reader in Information Systems and Director of the Graduate School, Brunel University, London, UK. Her research interests include human-computer interaction, cross-cultural issues in IT, affective computing and universal access. Xiaohui Liu is a professor of Computing, Department of Information System and Computing, and Head of the Centre for Intelligent Data Analysis, Brunel University, London, UK. His research interests include the understanding of individual differences in human behavior using data mining and development of novel intelligent data analysis methods for a variety of applications. Address for correspondence: Dr Ali Tarhini, 121 St. Johns Building, Department of Information system and Computing, Brunel University, London, UB8 3PH, UK. Email: Ali.Tarhini@brunel.ac.uk

[The copyright line for this article was changed on 28 September after original online publication]

\begin{abstract}
This paper examines the social, organisational and individual factors that may affect students' acceptance of e-learning systems in higher education in a cross-cultural context. A questionnaire was developed based on an extended technology acceptance model (TAM). A total sample of 1173 university students from two private universities in Lebanon and one university in England participated in this study. After performing the satisfactory reliability and validity checks, the hypothesised model was estimated using structural equation modeling. The findings of this study revealed that perceived usefulness (PU), perceived ease of use (PEOU), social norms (SNs), perceived quality of work life (QWL), computer self-efficacy (SE) and facilitating conditions (FC) are significant determinants of behavioural intentions (BIs) and usage of e-learning system for the Lebanese and British students. QWL, the newly added variable, was found the most important construct in explaining the causal process in the model for both samples. Differences were found between Lebanese and British students with regard to PEOU, SN, QWL, FC, SE and actual usage; however, no differences were detected in terms of PU and BI. Overall, the proposed model achieves acceptable fit and explains for $69 \%$ of the British sample and $57 \%$ of the Lebanese sample of its variance which is higher than that of the original TAM. Our findings suggest that individual, social and organisational factors are important to consider in explaining students' BI and usage of e-learning environments.
\end{abstract}

\section{Introduction}

The usage of e-learning, also known as web-based learning system, has been growing steadily during the last two decades. This growth is due to the increased competition among high educational institutions in order to attract students and meet their educational needs and goals (Clark \& Mayer, 2011) and to support both face-to-face and remote course delivery without the constraints of time and distance (Park, 2009). A web-based learning system is considered to be successful if it can replicate classroom experience and consider the students' needs 


\section{Practitioner Notes}

What is already known about the topic

- The generalisability and validity of technology acceptance model (TAM) is still questionable in terms of holding across cultures, particularly in non-western contexts.

- Various theoretical models, including TAM, have been widely used to explain users' behavioural intention (BI) and usage of technology.

- The acceptance and adoption of technology by students can be influenced by their cultural background.

- Student perception towards e-learning is important.

What this paper adds

- A cohesive investigation of the key factors that contribute to the acceptance of e-learning.

- Extends TAM to include social, organisational and individual factors and investigates whether those factors better help explaining and predicting the students' BI and usage of e-learning systems.

- Cross-cultural validation of TAM in an e-learning context to enhance its generalisability.

- Provides empirical evidence on the role of quality of work life (QWL), the newly added variable in the e-learning context, which was found the strongest predictor affecting the BI; this highlights the importance of including such factors in future research.

- Validation results confirm that British and Lebanese students are different in terms of perceived ease of use, social norms, QWL, facilitating conditions, computer selfefficacy and actual usage; however, no differences were detected in terms of PU and BI.

Implications for practice and/or policy

- Policy makers should consider the important role that individual, social and organisational factors play in explaining students' BI and usage of e-learning environments.

- Higher educational institutions should keep investing in technology and focus on decreasing obstacles related to adoption and implementation of technology integration in order to improve their students' learning experience.

- In cross-cultural settings, students' adoption and acceptance of e-learning may depend on their cultural background.

- In terms of subjective norm, it is necessary for instructors to put more emphasis on e-learning by announcing to the students that using the system is mandatory, and it is also advised that practitioners should persuade users who are familiar with the system to help promote it to other users by offering a greater variety of e-learning courses and advertising the benefits of e-learning to attract students.

- Policy makers should provide all facilities for the students to use the system including the necessary hardware and software. They should also emphasise on the importance of such technologies on enhancing the students' QWL.

- Both on- and off-line support in addition to training are necessary to increase e-learning self-efficacy. Additionally, providing a system which promotes ease of use and more user-friendliness could play a key role in enhancing learning effectiveness and efficiency. 
(Sanchez-Franco, 2010). If the students refuse to use the system, then its benefits will not be fully utilised (Tarhini, Hone \& Liu, 2013b). Additionally, although the internet may be considered as a global technology, the efficiency of such tools should also be measured locally as users usually work in local/national contexts (Li \& Kirkup, 2007; Teo, 2011).

Therefore, due to this phenomenon of the globalisation of web-based learning systems in education, it has become imperative for practitioners and policy makers to understand the user acceptance of such systems in order to enhance the students' learning experience (Liaw \& Huang, 2011). However, recent studies have shown that web-based learning system implementation is not simply a technological solution but also a process of many different factors, such as social factors (Tarhini, Hone \& Liu, 2013c; Teo, 2010), organisational such as facilitating conditions (FCs) (Sun \& Zhang, 2006) and individual factors such as computer efficacy (Liaw, 2008) in addition to behavioural and cultural factors. Such major factors play an important role in how the system is developed and used (Teo, Luan \& Sing, 2008; Zhang, Zhao \& Tan, 2008). The need to understand the acceptance and adoption of technology by students in the context in developing and developed countries highlights the importance of investigating the factors that influence the students' acceptance of technology.

Various theoretical models have been developed (the theory of reasoned action, the theory of planned behaviour, innovation diffusion theory, unified theory of acceptance and use technology, the technology acceptance model [TAM]) to investigate and explore the determinants of user's behaviour towards adoption and using information technology. This study employs the TAM (Davis, 1989) due to its acceptable explanatory power and popularity in a number of application areas (Venkatesh \& Bala, 2008). Since it has been developed, TAM has been extensively used, tested and extended to explain technology adoption and success in a number of application areas (eg, Bagozzi, 2007; Yousafzai, Foxall \& Pallister, 2007) and in e-learning context (eg, Park, 2009; Sánchez \& Hueros, 2010; Teo, 2009b, 2011; Zhang et al, 2008).

Although the TAM measures and predicts the acceptance and usage level of technology, there have been some criticisms concerning the theoretical contributions of the model, specifically its ability to fully explain technology adoption and usage (eg, Bagozzi, 2007; Benbasat \& Barki, 2007; Straub \& Burton-Jones, 2007). Consequently, the existing parameters of the TAM neglected investigating other essential predictors and factors that may affect the adoption and acceptance of technology, such as social, organisational and individual factors. Additionally, in a cross-cultural context, TAM has been criticised for showing bias (McCoy, Everard \& Jones, 2005; Straub, Keil \& Brenner, 1997). For example, Straub et al (1997) applied TAM in Japan, USA and Switzerland. They found that TAM produced similar results between the USA and Switzerland, but different results were noticed between the USA and Japan. Furthermore, many TAM studies focus on western/developed countries, while TAM has not been widely tested within nonwestern/developing countries (Teo et al, 2008). Consequently, Teo et al (2008) emphasise on the importance of testing the TAM in different cultures as it is argued that when Davis developed the TAM (Davis, 1989), he did not take into consideration the unbiased reliability of TAM in crosscultural settings. Additionally, the applicability of TAM is limited in the educational settings as much of the research has been carried out in non-educational contexts.

Faced with these limitations, this study aims to add new variables, namely social norms (SNs), quality of work Life (QWL), computer self-efficacy (SE) and FCs, to the proposed research model to investigate the extent to which these variables affect students' willingness to adopt and use web-based learning systems and investigate whether there are differences among these factors between developing and developed world, specifically Lebanon as developing world and England as developed world, in addition to Blackboard as a web-based learning system. Blackboard is considered one of the most popular web-based learning system tools in higher education today as 
Table 1: Cultural differences between England and Lebanon on Hofstede's cultural dimensions

\begin{tabular}{lcccc}
\hline Country & Power distance & Masculinity & Individualism & Uncertainty avoidance \\
\hline Lebanon (Arab countries) & 80 & 53 & 38 & 68 \\
England & 35 & 66 & 89 & 35 \\
\hline
\end{tabular}

Values adopted from Hofstede \& Hofstede, 2005.

it provides a framework for course delivery in addition to its ease of use by learners (Carvalho, Areal \& Silva, 2011). According to Blackboard Inc. (2012), it is defined as "the comprehensive technology platform for teaching and learning, community building, content management and sharing, and measuring learning outcomes and consists of integrated modules, with a core set of capabilities that work together." It integrates communication tools, including a bulletin board, chat room and private e-mail. In addition graphics, video and audio files can be included into a Blackboard site. Blackboard also provides instructional tools to support course content such as a glossary, references, self-test and quiz module. Students, too, can place assignments and other materials in Blackboard for courses in which they are enrolled. Furthermore, Blackboard also gives academic staff course management tools for grading, tracking student interaction and monitoring class progress (Iskander, 2008). Such features can facilitate interaction between academic staff and students (Iskander, 2008).

Extending the TAM model to include social, organisational and individual factors in two cultures allows us to explore the generalisability and applicability of the proposed model in the context of web-based learning system in two cultures and also allows exploration of where differences may lie between the cultures involved. This will also help policy makers and practitioners to gain a deeper understanding of the students' acceptance of web-based learning systems.

As shown in Table 1, England and Lebanon were chosen for this study because they represent nearly reverse positions on all cultural dimensions presented by Hofstede and Hofstede (2005). England is high on individualism and masculinity but low in power distance and uncertainty avoidance. On the other hand, Lebanon is low on individualism, moderate on masculinity, and high on power distance and uncertainty avoidance. In addition, compared with England, Lebanon remains relatively unexplored in terms of technology acceptance, and the investment in technology in the educational system is still immature compared with western countries as universities and higher education institutions support traditional styles of pedagogy in education due to the lack of financial resources or trained staff (Baroud \& Abouchedid, 2010; Nasser \& Abouchedid, 2000; UNDP, 2002) which in turn may affect the acceptance of technology within such countries. These differences also demonstrate the importance of understanding the role of cross-cultural studies. Additionally, the limitations that emerge from TAM especially on holding equally well across cultures and the inconsistency in previous studies' results (Gefen \& Straub, 1997; McCoy, Galletta \& King, 2005; Srite \& Karahanna, 2006; Teo et al, 2008) direct our research to a cross-cultural comparison between those two countries.

The paper is structured as follows. The second section presents and explains our research model and describes the research hypotheses in detail. This is followed by the research method that guided the research in the third section. The fourth section presents the results of the proposed model. Finally, the fifth section discusses the main findings of the study and concludes the paper.

\section{Theoretical framework}

This paper highlights previous literature that used TAM in an educational context and proposes an e-learning conceptual model based on extended TAM. The model includes SN, QWL, SE and FC 


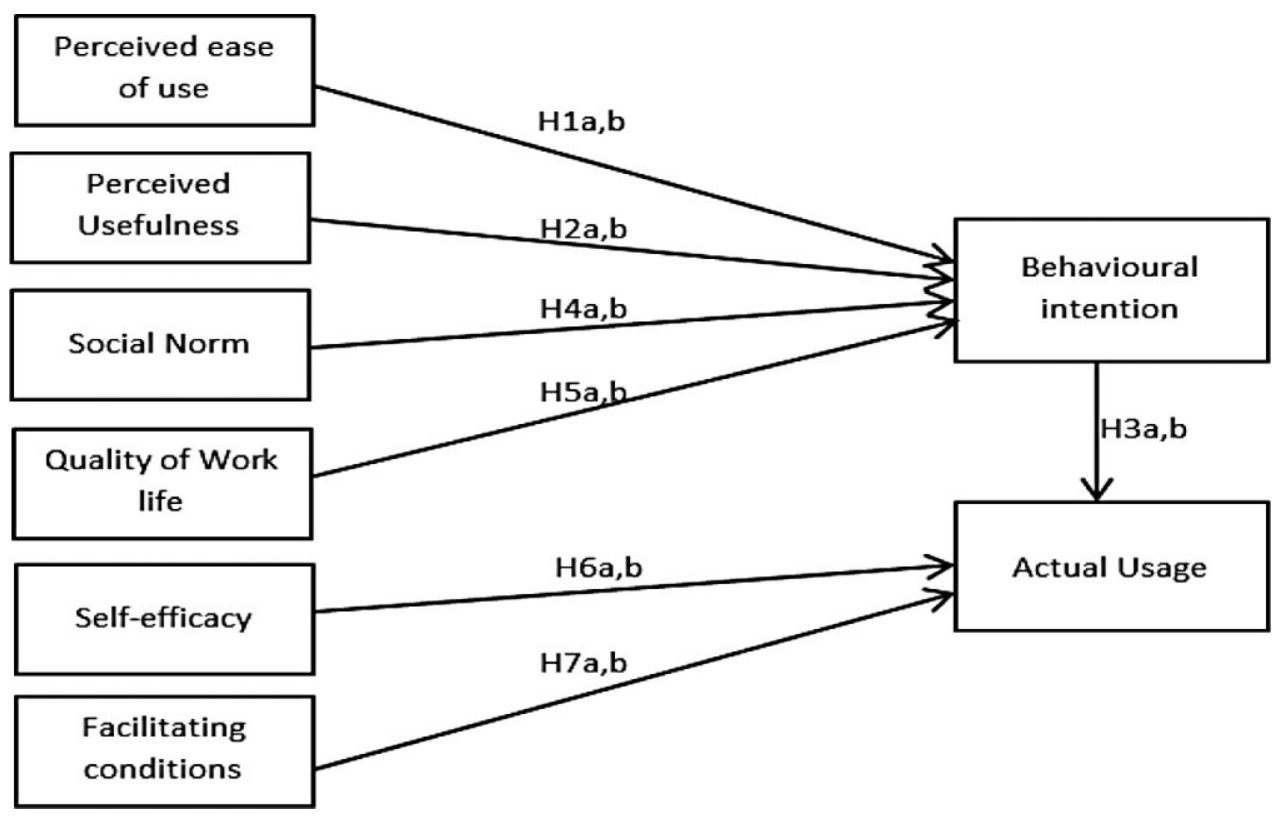

Figure 1: The theoretical framework

as additional predictor variables within the extended TAM. Figure 1 presents the overall conceptual model, and the sections that follow illustrate and explain all of the predicted relationships of the previous literature studies.

\section{TAM model}

Perceived ease of use (PEOU) is defined as "the degree to which a person believes that using a particular system would be free of effort" (Davis, Bagozzi \& Warshaw, 1989, p 320). In the TAM and TAM2, PEOU was theorised as a direct determinant of behavioural intention (BI). Reviewing the literature, the majority of the subsequent studies about student perceptions on using technologies supports the important role that PEOU plays in predicting the BI (Chang \& Tung, 2008; Liu, Chen, Sun, Wible \& Kuo, 2010; Park, 2009; Tarhini, Hone \& Liu, 2013a; Teo \& Noyes, 2011). However, the degree of significance was different between the findings in the literature. The difference in the findings was based on the field of study, sample size or techniques used for analysing the data. For example, Peng, Su, Chou and Tsai (2009) found that PEOU was the strongest determinant on the intention to use the system, which supported the findings of Chang and Tung's (2008) study. Furthermore, Saeed and Abdinnour-Helm (2008) found that PEOU have a direct and significant influence on BI. However, it was not the strongest predictor on the BI to use to the system. In contrast, Chesney (2006) concluded that PEOU did not have a direct and significant influence on the intention to use the system.

In the context of this study, the inclusion of PEOU was to investigate students' beliefs of whether the system is free of effort and to predict their BI to use the Blackboard system. It is expected that if the students find the Blackboard system easy to use, then they are more likely to adopt and use the system. Therefore, we propose the following hypothesis:

H1a,b: PEOU will have a direct positive influence on students' BI to use web-based learning system in the British and Lebanese context.

Perceived usefulness (PU) is defined as "the degree to which a person believes that using a particular system would enhance his/her job performance” (Davis, 1989, p 453). In the TAM, 
TAM2 and augmented TAM, PU was theorised as a direct determinant of BI. Compared to the other behavioural belief construct (PEOU), PU was found to have a significantly greater correlation with BI than did PEOU (Davis, 1989), and the same result has been found in e-learning studies (Chang \& Tung, 2008; Liu et al, 2010). Davis (1989) concluded that users are mostly driven to adopt and use the system primarily because of the functions it performs for them.

Many research studies have highlighted the important role that PU plays on BI to use web-based learning tools (Chang \& Tung, 2008; Liu et al, 2010; Rodriguez \& Lozano, 2011). For example, Liu et al (2010) applied an extended TAM to explore the factors that affect the intention to use an online learning community. They found that PU was the most influential variable in predicting the intention to use the web-based learning system. In contrast, Saeed and Abdinnour-Helm (2008) found that PU has an influence on the intention to use but was not the most influential factor.

In the present context of the study, PU was used to investigate the students' beliefs about the potential benefits in using the Blackboard system. In this cross-sectional study and in accordance with the TAM, it is expected that if students think that the Blackboard system is useful and will add value to their education, then they are more likely to adopt and use the system. In contrast, students may resist educational technologies if they are sceptical of their educational value. Therefore, we propose the following hypothesis:

H2a,b: PU will have a direct positive influence on students' BI to use web-based learning system in the British and Lebanese context.

$\mathrm{BI}$ is considered to be an immediate antecedent of actual usage (AU) and gives an indication about an individuals' willingness to perform a specific behaviour. There is a good support in the literature for the relationship between BI and AU in the e-learning context (Chang \& Tung, 2008; Park, 2009; Zhang et al, 2008). Thus, we propose the following hypothesis:

H3a,b: BI will positively influence the actual use of web-based learning system in the British and Lebanese context.

SNs impact usage behaviour

$\mathrm{SN}$ is defined as "the person's perception that most people who are important to him or her think he or she should or should not perform the behaviour in question" (Ajzen \& Fishbein, 1980). Although SN was found to be an important determinant of technology acceptance and usage based on TRA and TPB (Ajzen, 1991), TAM excluded the SN due to theoretical and measurement problems (see Davis et al, 1989). This research extended the TAM model to include the SN factor; we believe that it is important to integrate the SN in the TAM model as we assume that the effect of $\mathrm{SN}$ on $\mathrm{BI}$ is crucial in multi-religious, multi-ethnic countries like England and Lebanon. As mentioned by Venkatesh, Morris, Davis and Davis (2003), the influence of SN is very complex. SN has been characterised in some research as an antecedent of $\mathrm{BI}$ and in other studies as an antecedent PU. There has also been some inconsistency in the literature about the influence of SN on the intention to use the technology. For example, many researchers found a significant impact of SN on BI (Venkatesh \& Davis, 2000; Venkatesh \& Morris, 2000), while a number of others failed to find any impact (eg, Chau \& Hu, 2002; Lewis, Agarwal \& Sambamurthy, 2003). In the current paper, SN will be measured by the influence of other colleagues and instructors on students' perception to use the web-based learning system. Therefore, we propose the following hypothesis:

H4a,b: SN will have a positive influence on student's BI to use and accept the e-learning technology in the British and Lebanese context.

QWL

The QWL in a broader sense seeks to achieve integration among technological, human and societal demands (Cascio \& McEvoy, 2003). This research extends the TAM model to integrate QWL due 
to its importance in technology acceptance in previous Information System empirical studies (eg, Kripanont, 2007; Srite \& Karahanna, 2000; Zakour, 2004). This has not previously been considered within an educational context, and the current paper therefore explores whether it plays a role within this context. It is expected that introducing the QWL construct will enable a better capturing of cultural difference on the acceptance of e-learning systems between Lebanon and England respectively. For this paper, QWL is defined in terms of student's perception and belief that using technology will enhance the students' QWL such as saving expenses and time when downloading e-journals or when communicating via email with their instructors and colleagues. Therefore, it is hypothesised:

H5a,b: QWL will have a positive influence on student's BI to use the web-based learning system in the British and Lebanese context.

\section{SE}

As an individual factor, SE has been defined as the belief "in one's capabilities to organise and execute the courses of action required to produce given attainments" (Bandura, 1997, p 2). SE is a type of self-assessment that helps understanding human behaviour and performance in a certain task (Bandura, 1997). SE was shown to be an important predictor in determining a persons' actual behaviour in e-learning context (Roca, Chiu \& Martínez, 2006). Therefore, it is expected that users with high SE are more likely to accept and use an e-learning system than those of low SE.

H6a,b: SE will have a positive influence on the AU of the web-based learning system in the British and Lebanese context.

FCs

As an organisational factor, FC has been defined as "the degree to which an individual believes that an organisational and technical infrastructure exists to support use of the system" (Venkatesh et al, 2003). More specifically, it refers to the availability of external resources (time, money and effort) and also the technological resources (PCs, broadband, etc) needed to facilitate the performance of a particular behaviour. This factor was found to be a significant predictor of AU in the field of technology acceptance studies (Venkatesh et al, 2003) and within the e-learning context (Maldonado, Khan, Moon \& Rho, 2009; Teo, 2009a). Therefore, it is very important to investigate whether FC has a direct influence on the AU of the e-learning system as the absences of facilitating resources may represent barriers to usage (Taylor \& Todd, 1995, p 153). Given the discussion above, the researchers propose the following hypothesis:

H7a,b: FCs will have a positive influence on AU of web-based learning system in the British and Lebanese context.

\section{Methodology}

Procedure

Students from different disciplines were invited to participate in this study through a face-to-face invitation by the researcher during the study term. The participation in the study was completely voluntary, and students were briefed about the purpose of the study and informed of their rights not to participate and withdraw from completing the questionnaire at any time. No financial incentive or rewards in kind was offered.

\section{Sample}

In line with empirical research in technology acceptance (Venkatesh \& Bala, 2008; Venkatesh et al, 2003) and e-learning (Tarhini et al, 2013b; Teo et al, 2008; Zhang et al, 2008), this study employed a quantitative research approach to test the proposed model (see Figure 1). It is based on a non-probabilistic and self-selection sampling method (ie, convenience sampling) as it enables the researcher to collect data from the participants based on their availability. It also helps the researcher to improvise with the resource available for the research especially when there is lack 
Table 2: Descriptive statistics of the constructs for the two samples

\begin{tabular}{lcccccccc}
\hline & \multicolumn{3}{c}{ England } & & \multicolumn{3}{c}{ Lebanon } \\
\cline { 3 - 4 } Construct & Mean & $\begin{array}{c}\text { Standard } \\
\text { deviation }\end{array}$ & $\begin{array}{c}\text { Cronbach's } \\
\text { alpha }\end{array}$ & & Mean & $\begin{array}{c}\text { Standard } \\
\text { deviation }\end{array}$ & $\begin{array}{c}\text { Cronbach's } \\
\text { alpha }\end{array}$ & t-Test \\
\hline PEOU & 5.37 & 1.3 & .92 & & 5.66 & 1.06 & .90 & $4.20^{* *}$ \\
PU & 5.23 & 1.26 & .92 & & 5.2 & 1.10 & .90 & -1.25 \\
SNs & 4.86 & 1.34 & .83 & & 5.00 & 1.16 & .74 & $2.5^{*}$ \\
QWL & 5.55 & 1.30 & .89 & & 5.39 & 1.00 & .83 & $-2.4^{*}$ \\
FCs & 5.04 & 1.53 & .88 & & 5.44 & 1.10 & .90 & $2.4^{*}$ \\
SE & 4.95 & 1.13 & .84 & & 5.2 & 0.98 & .86 & $3.06^{* *}$ \\
BI & 5.67 & 1.27 & .89 & & 5.63 & 1.13 & .87 & -0.56 \\
AU & 4.42 & 1.21 & .72 & & 4.21 & 1.01 & .70 & $-3.4^{* *}$ \\
\hline
\end{tabular}

${ }^{*} p<.05 ;{ }^{* *} p<.01$. AU, actual usage; BI, behavioural intention; FC, facilitating condition; PEOU, perceived ease of use; PU, perceived usefulness; QWL, quality of work life; SE, self-efficacy; SN, social norm.

of time and financial resources. More specifically, the empirical data were collected in England and Lebanon by means of self-administrated questionnaire containing 38 questions. However, in a statistical meta-analysis study of applying the TAM within the field of information system, King and He (2006) used 88 published studies to analyse the conditions where TAM may produce different results based on user types and usage types; they included that "in terms of type of user and type of use demonstrated that professionals and general users produce quite different results. However, students, who are often used as convenience sample respondents in TAM studies, are not exactly like either of the other two groups.” As students share many similarities and thus produce similar results (King \& He, 2006), data were collected from only one university from Lebanon and two universities from England. Therefore, the effect of this method on generalisability of the results is decreased to minimum.

The target sample for this survey was British and Lebanese students that use e-learning system provided by their university. These students were full-time students enrolled in various courses offered by different departments (Business, Economics, Information system and social science) at the masters or undergraduate degrees from one university in England located in London and two universities in Lebanon located in Beirut. A total of 2000 questionnaires were distributed to 1000 students from the UK and 1000 from Lebanon respectively, of which 1220 were returned indicating a $61 \%$ response rate. After screening for missing data and duplicated responses, we retained 1173 questionnaires for data analysis. These included 596 Lebanese participants and 604 British participants. The age range varied between 17 and 35 years old.

The Lebanese sample was 53.8\% male (306), with 64.1\% (366) undergraduates and with 58\% experienced in using computer and internet usage. The UK sample was 50.5\% male (305), with $71 \%$ undergraduates and 64\% experienced in using computer and internet usage. Table 2 presents the demographic characteristics of the respondents.

\section{Instrument development}

The researcher developed the questionnaire items (questions) based on the objectives of the study and previous literature review, where they were quoted to be reliable and valid to measure constructs of the phenomena that they intend to represent. The questionnaire was first pre-tested for content validity. We administered the questionnaire to five professors and five PhD students who were mainly in the Department of Information System at Brunel University in order to modify our initially proposed items or to suggest additional ones. Content validity and reliability were checked by pilot testing the instrument with 40 students from Lebanon and England. The main purpose of 
the pilot study was to ensure the readability and clarity of the questionnaire items and to check if the data collected answer the investigated questions and provide face validity (Sekaran \& Bougie, 2011; Zikmund, 2009). Based on the feedback and suggestions from the potential participants (students), very minor changes were suggested on the question wording and the questionnaire layout by the respondents, and thus, face validity was established. Also, the results of the Cronbach's alpha were all above 0.7 which suggest that the constructs had adequate reliability.

Most of the items used in the questionnaire use a 7-point Likert scale, ranging from 1 (strongly disagree) to 7 (strongly agree), while AU construct uses scales from 1 to 6 (1 [less than once a month] and 6 [several times a day]) to measure the frequency of using web-based learning system and ( 1 [almost never] and 6 [more than 3 hours]) to measure the average of daily usage per hour. The items used to measure the main TAM constructs (PEOU, PU) were measured using five items, while BI and AU were measured using three items. These items were adapted from the work of Davis (1989), Ngai, Poon and Chan (2007) and Pituch and Lee (2006). The extended TAM determinants (SE, FCs, SN, QWL) were measured using five items and were adapted from the work of Kripanont (2007), Venkatesh et al (2003), Schepers and Wetzels (2007), Park (2009) and Wang, Wu and Wang (2009).

\section{Analysis and results}

The data analysis of the study was conducted in two phases. The first phase examined the measurement model to examine reliability and validity of the model, whereas the second phase involved the analysis of the structural model and hypotheses testing.

\section{Descriptive statistics}

Table 2 presents the results of descriptive statistics of the variables used in the model. All means were greater than 4.42 for the British sample $(\mathrm{N}=604)$ and 4.21 for the Lebanese sample $(\mathrm{N}=569)$ which indicate that the majority of participants expresses generally positive responses to the constructs used in this study.

The standard deviation values showed a narrow spread around the mean. Table 3 also included the results of an independent samples $t$-test (degrees of freedom $[d f]=1171$ ).

Table 3: Model fit summary for the final measurement and structural model for British and Lebanese sample

\begin{tabular}{|c|c|c|c|c|c|}
\hline \multirow[b]{2}{*}{ Fit index } & \multirow[b]{2}{*}{$\begin{array}{l}\text { Recommended value } \\
\text { Hair et al (2010) }\end{array}$} & \multicolumn{2}{|c|}{ England } & \multicolumn{2}{|c|}{ Lebanon } \\
\hline & & $\begin{array}{l}\text { Measurement } \\
\text { model }\end{array}$ & $\begin{array}{l}\text { Structural } \\
\text { model }\end{array}$ & $\begin{array}{l}\text { Measurement } \\
\text { model }\end{array}$ & $\begin{array}{l}\text { Structural } \\
\text { model }\end{array}$ \\
\hline$\chi^{2}$ & $p<.05$ & 841.17 & 895.46 & 979.83 & 1001.17 \\
\hline$\tilde{d} f$ & $\mathrm{n} / \mathrm{a}$ & 349 & 355 & 405 & 410 \\
\hline$\chi^{2} / d f$ & $<5$ preferable $<3$ & 2.41 & 2.52 & 2.41 & 2.46 \\
\hline GFI & $>0.90$ & .91 & .90 & .90 & .90 \\
\hline AGFI & $>0.80$ & .88 & .88 & .87 & .86 \\
\hline CFI & $>0.90$ & .96 & .96 & .95 & .95 \\
\hline RMSR & $<0.10$ & .06 & .07 & .08 & .08 \\
\hline RMSEA & $<0.08$ & .05 & .05 & .05 & .05 \\
\hline NFI & $>0.90$ & .94 & .93 & .92 & .91 \\
\hline PNFI & $>0.60$ & .81 & .82 & .80 & .80 \\
\hline
\end{tabular}

AGFI, Adjusted Goodness-of-Fit Index; CFI, Comparative Fit Index; $d f$, degrees of freedom; GFI, Goodness-ofFit Index; NFI, Normed Fit Index; PNFI, Parsimony Normed Fit Index; RMSEA, root mean square error of approximation; RMSR, root mean square residuals. 
Table 4: Construct reliability, convergent validity and discriminant validity for the British sample

\begin{tabular}{|c|c|c|c|c|c|c|c|c|c|c|}
\hline & $C R$ & $A V E$ & $B I$ & $P U$ & PEOU & $S E$ & $F C$ & $S N$ & $Q W L$ & $A U$ \\
\hline BI & .90 & .75 & .86 & & & & & & & \\
\hline PU & .93 & .71 & .72 & .84 & & & & & & \\
\hline PEOU & .93 & .72 & .65 & .66 & .85 & & & & & \\
\hline SE & .90 & .76 & .59 & .57 & .62 & .87 & & & & \\
\hline $\mathrm{FC}$ & .89 & .74 & .62 & .58 & .58 & .65 & .86 & & & \\
\hline SN & .84 & .63 & .51 & .52 & .39 & .39 & .46 & .79 & & \\
\hline QWL & .89 & .62 & .77 & .71 & .58 & .50 & .56 & .44 & .79 & \\
\hline $\mathrm{AU}$ & .72 & .57 & .70 & .63 & .53 & .84 & .72 & .47 & .52 & .76 \\
\hline
\end{tabular}

AU, actual usage; AVE, average variance extracted; BI, behavioural intention; CR, composite reliability; FC, facilitating condition; PEOU, perceived ease of use; PU, perceived usefulness; QWL, quality of work life; SE, self-efficacy; SN, social norm.

\section{Analysis of measurement model- examination of reliability and validity}

A confirmatory factor analysis (CFA) based on AMOs 18.0 was used to examine the relationships among the constructs within the proposed model (Arbuckle, 2009). We adopt the maximum likelihood method to estimate the model's parameters where all analyses were conducted on variance-covariance matrices (Hair, Black, Babin, Anderson \& Tatham, 2010). There are some fit indices that should be considered in order to assess the model goodness-of-fit (Hair et al, 2010; Kline, 2005). First, it was determined using the minimum fit function $\chi^{2}$. However, the $\chi^{2}$ was not appropriate to the sample size (Hu \& Bentler, 1999); the ratio of the $\chi^{2}$ static to its degree of freedom $\left(\chi^{2} / d f\right)$ was used, whereas the value should be less than 3 to indicate a good fit of the data (Carmines \& McIver, 1981). Hair et al (2010) suggest the following indices to indicate acceptable fit: "Goodness of Fit Index (GFI); Normed Fit Index (NFI); Parsimony Normed Fit Index (PNFI); Root Mean Square Residuals (RMSR); Comparative Fit Index (CFI); Adjusted Goodness-of-Fit Index (AGFI); the Root Mean Square Error of Approximation (RMSEA).” Table 3 shows the level of acceptance fit and the fit indices for the British and Lebanese sample after the improvement in model fit.

To ensure a good fit model, some indicators (SE4, FC4, SN4) have to be deleted from the initial measurement model for the British sample, whereas for the Lebanese sample, one pair of measurement error terms was correlated (e22 $\leftrightarrow \mathrm{e} 23$ ) which are related to FC3 and FC4 respectively; in addition, one indicator (SE4) has to be deleted from the initial measurement model. The process was to delete one indicator at a time and then re-estimate the model (see Table 3).

The results of the CFA have shown the good measurement model fit to the data for the proposed model for both the British and Lebanese samples respectively (see Table 3). Therefore, the next step is to assess convergent validity and discriminant validity in addition to reliability in order to evaluate that the psychometric properties of the measurement model are adequate, which can be found in terms of composite reliability (CR) and average variance extracted (AVE) (Hair et al, 2010). The results can be shown in Tables 4 and 5 respectively.

\section{British sample}

Average variance extracted and $\mathrm{CR}$ were used to estimate the reliability and convergent validity of the factors. Hair et al (2010) suggest that "the CR value should be greater than 0.6 and that the AVE should be greater than 0.5." The average extracted variances within the British sample were all above 0.57 and above 0.73 for CR (see Table 4). Therefore, all factors have adequate reliability and convergent validity. Additionally, with the exception of AU, the total AVE of the average value 
Table 5: Construct reliability, convergent validity and discriminant validity for the Lebanese sample

Factor correlation matrix with $\sqrt{ } A V E$ on the diagonal

\begin{tabular}{lcccccccccc}
\hline & $C R$ & $A V E$ & $B I$ & $P U$ & PEOU & $S E$ & $F C$ & $S N$ & $Q W L$ & $A U$ \\
\hline BI & .87 & .70 & .84 & & & & & & & \\
PU & .91 & .66 & .54 & .81 & & & & & & \\
PEOU & .93 & .73 & .53 & .518 & .85 & & & & & \\
SE & .89 & .74 & .51 & .333 & .53 & .86 & & & & \\
FC & .88 & .67 & .45 & .297 & .50 & .62 & .82 & & & \\
SN & .80 & .51 & .44 & .357 & .33 & .38 & .35 & .71 & & \\
QWL & .84 & .52 & .68 & .571 & .48 & .45 & .47 & .43 & .72 & \\
AU & .70 & .50 & .64 & .451 & .39 & .53 & .57 & .36 & .45 & .70 \\
\hline
\end{tabular}

AU, actual usage; AVE, average variance extracted; BI, behavioural intention; CR, composite reliability; FC, facilitating condition; PEOU, perceived ease of use; PU, perceived usefulness; QWL, quality of work life; SE, self-efficacy; SN, social norm.

of variables employed within the proposed model is larger than their correlation value; thus, there were discriminant validity issues. However, as AU is measured by two items only, deleting one of the variables might cause unidentification problems; therefore, we established discriminant validity.

\section{Lebanese sample}

The average extracted variances within the Lebanese sample were all above 0.50 and above 0.70 for CR (see Table 5). This means that all factors have adequate reliability and convergent validity. Additionally, the total AVE of the average value of variables used for the research model is larger than their correlation value; therefore, we also established discriminant validity.

Consequently, the internal consistency of each construct within the Lebanese sample was assessed using Cronbach's alpha. Cronbach's alpha measures how well a set of items measures a single unidirectional latent construct. The value of Cronbach's alpha for all factors in the model (see Table 2) had a coefficient which ranges from 0.70 to 0.95 and exceeded the cut-off value of 0.7 for both samples (DeVellis, 2003; Robinson, Wrightsman \& Andrews, 1991). Therefore, the result indicates that the constructs within the two samples had adequate reliability.

\section{Analysis of the structural model and hypotheses testing}

Based on the same criteria used for measurement model to measure the goodness-of-fit for the proposed model, the results of the structural model were very close to the measurement model which provides firm evidence of a good model data fit (see Figure 2). The next step is examining the hypothesised relationships within the model.

Figure 2 and Table 6 present the standardised path coefficients among the constructs in the model for the British and Lebanese samples. In terms of the British sample, all the hypothetical relationships were supported $(p<.001)$ by the data. PEOU $(\gamma=0.189)$, PU $(\gamma=0.179)$, SN $(\gamma=0.117)$ and QWL $(\gamma=0.455)$ were found to have a significant positive impact on BI towards using Blackboard, with QWL having the strongest magnitude on the relationship with BI. These results provide support for $\mathrm{H} 1 \mathrm{a}, \mathrm{H} 2 \mathrm{a}, \mathrm{H} 4 \mathrm{a}$ and $\mathrm{H} 5 \mathrm{a}$. On the other hand, the results implies that the SE $(\gamma=0.284), \mathrm{FC}(\gamma=0.1)$ and BI $(\beta=0.167)$ had a positive significant influence on the AU of the Blackboard system, thus supporting H3a, H6a and H7a. PEOU, PU, SN and QWL account for $69 \%\left(R^{2}=0.69\right)$ of the variance of BI, with QWL contributing the most to BI compared with the other constructs. 


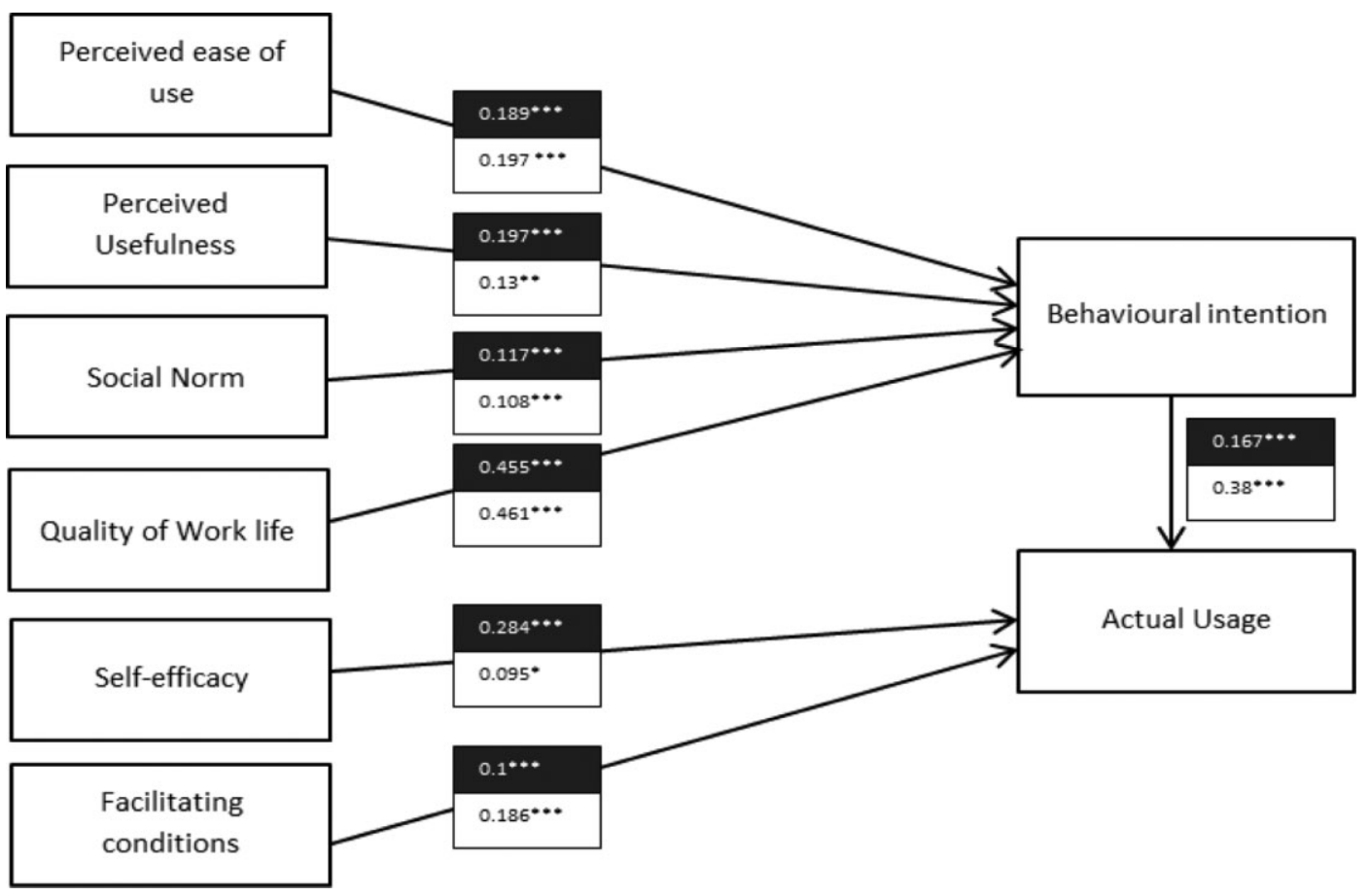

Figure 2: The research model results. Coefficients for British are in the shaded boxes. ${ }^{*} \mathrm{p}<.05 ;{ }^{* *} \mathrm{p}<.01$; ${ }^{* * *} \mathrm{p}<.001 ; \mathrm{NS} \mathrm{p}>.01$

Table 6: The summary of the hypothesised relationships of the British and Lebanese samples

\begin{tabular}{llccc}
\hline Hypothesis & $\begin{array}{c}\text { Proposed } \\
\text { relationship }\end{array}$ & $\begin{array}{c}\text { Path coefficient: } \\
\text { UK }\end{array}$ & $\begin{array}{c}\text { Path coefficient: } \\
\text { Lebanon }\end{array}$ & $\begin{array}{c}\text { Study } \\
\text { results }\end{array}$ \\
\hline H1a,b & PEOU $\rightarrow$ BI & $.189^{* * *}$ & $.197^{* * *}$ & Supported \\
H2a,b & $\mathrm{PU} \rightarrow \mathrm{BI}$ & $.197^{* * *}$ & $.130^{* *}$ & Supported \\
$\mathrm{H} 3 \mathrm{a}, \mathrm{b}$ & $\mathrm{BI} \rightarrow \mathrm{AU}$ & $.167^{* * *}$ & $.380^{* * *}$ & Supported \\
$\mathrm{H} 4 \mathrm{a}, \mathrm{b}$ & $\mathrm{SN} \rightarrow \mathrm{BI}$ & $.117^{* * *}$ & $.100^{* * *}$ & Supported \\
$\mathrm{H} 5 \mathrm{a}, \mathrm{b}$ & $\mathrm{OWL} \rightarrow \mathrm{BI}$ & $.445^{* * *}$ & $.461^{* * *}$ & Supported \\
$\mathrm{H} 6 \mathrm{a}, \mathrm{b}$ & $\mathrm{SE} \rightarrow \mathrm{AU}$ & $.284^{* * *}$ & $.095^{*}$ & Supported \\
$\mathrm{H} 7 \mathrm{a}, \mathrm{b}$ & $\mathrm{FC} \rightarrow \mathrm{AU}$ & $.1^{* * *}$ & $.186^{* * *}$ & Supported \\
\hline
\end{tabular}

${ }^{*} p<.05 ;{ }^{* *} p<.01 ;{ }^{* * *} p<.001$; not-significant $p>.01$. AU, actual usage; BI, behavioural intention; FC, facilitating condition; PEOU, perceived ease of use; PU, perceived usefulness; QWL, quality of work life; SE, self-efficacy; SN, social norm.

In terms of the Lebanese sample and as expected, the results shows that BI towards using Blackboard system was found to be positively influenced by PEOU $(\gamma=0.193, p<.001)$, PU $(\gamma=0.13, p<.01)$, SN $(\gamma=0.108, p<.001)$ and QWL $(\gamma=0.461, p<.001)$, and similar to the British sample, QWL had the strongest magnitude on the relationship with BI, thus supporting $\mathrm{H} 1 \mathrm{~b}, \mathrm{H} 2 \mathrm{~b}, \mathrm{H} 4 \mathrm{~b}$ and H5b. Finally, the results implies that $\mathrm{SE}(\gamma=0.095, p<.05)$, FC $(\gamma=0.185, p<.001)$ and BI $(\beta=0.380, p<.001)$ had a positive significant influence on the AU of the Blackboard system. This means that H3b, H6b and H7b were supported. Altogether, the model accounted for $57 \%\left(R^{2}=0.57\right)$ of the variance of BI, with QWL contributing the most to BI compared with the other constructs. 


\section{Discussion and conclusion}

The aim of this study was to extend the TAM model by incorporating new variables, namely SN, QWL, SE and FCs, to the model to explore the extent to which these variables affect students' intention to adopt and use e-learning systems and explore whether there are differences among these factors between British and Lebanese students.

Similar to earlier studies (Park, 2009; Teo et al, 2008), our results support theoretically and empirically the ability of TAM to be a useful theoretical framework for better understanding the student's acceptance of e-learning technology. In general, the results show that the majority of participants in the British and Lebanese sample expresses generally positive responses to the constructs being measured in the model. This means that both British and Lebanese students are willing to embrace e-learning as part of their repertoire of learning opportunities. Our results are in contrast with previous literature which suggests that web-based learning system in Lebanon is still immature compared with western countries as universities and higher education institutions support traditional styles of pedagogy in education due to the lack of financial resources or trained staff (Baroud \& Abouchedid, 2010; Nasser \& Abouchedid, 2000; UNDP, 2002).

More specifically, the findings of the general structural model show that all the predictors (PEOU, PU, SN, QWL, SE) were found to be significant determinants of BIs and usage of e-learning system, with QWL as the most important construct in explaining the causal process in the model for both samples. While no differences were found between Lebanese and British students in terms of PU and BI, differences were found in terms of PEOU, SN, QWL, FC, SE and AU.

In terms of behavioural beliefs (PEOU and PU), the results shows that PU contributed the most to BI compared with the PEOU. Our results are in accordance with TAM model and previous literature (eg, Davis et al, 1989; Liu et al, 2010), which posits that PU plays an important role in predicting the BI towards using technology. In this context, it is therefore believed that students who find the system useful in their learning process and also find the system easy to use are more likely to adopt the system. Therefore, in order to attract more users of e-learning, instructors should improve the content quality of their e-learning systems by providing sufficient, up-to-date content that can fit the students' needs. In order to promote the ease of use of e-learning, system designers should provide a system which promotes ease of use.

QWL has been found to be the most important construct in explaining the causal process in the model for both samples. The demonstration that QWL is important in the e-learning context also suggests that system designers should pay attention to providing systems that address this concern and that educators should explain the benefits of e-learning in terms that relate to this construct. Additionally, this finding should inspire not only organisations but also the government in promoting the importance of introducing a new technology on the users' QWL.

We have also found that SN is a significant determinant on BI to use e-learning especially in the Lebanese sample. In this context, the instructor should announce to the students that using the system is mandatory, and it is also advised that practitioners should persuade users who are familiar with the system to help in promoting it to other users. Thus, when the number of e-learning users reaches a critical mass point, the numbers of later e-learning adopters are likely to grow rapidly (Rogers, 2003). This emphasises the need to consider implementation strategies that develop buy-in from those within the wider social environment.

As mentioned above, FCs has been found to be an important factor that positively influences AU of the web-based learning system. This construct is found to be less influential for less experienced users. Therefore, through categorisation of the users into segments, the management may decrease the time and money constraints and thus provide efficient technical support in case they know the category the students belong to. In addition, university administrators can improve their strategic decision making about technology in the future. 
Self-efficacy has been found to play an important role in predicting student's BI to use the e-learning. It is clear that individuals with higher self-efficacy induce a more active learning process (Chung, Park, Wang, Fulk \& McLaughlin, 2010). Therefore, IT teams should provide both on- and off-line support in addition to training, and this is necessary to increase e-learning self-efficacy. Training is very useful in boosting self-confidence in the use of technology, and eventually, individuals who demonstrate higher self-confidence in using technology are more likely to use the system.

Overall, the proposed model achieves acceptable fit and explains for $69 \%$ of the British sample and $57 \%$ of the Lebanese sample of its variance of which is higher than that of the original TAM. Our findings suggest that individual, social and organisational factors are important to consider in explaining students' BI and usage of e-learning environments. In this context, all the major and different individual factors should be considered simultaneously because only then a more complete picture of the dynamic nature of individual technology may begin to emerge.

Generally speaking, we do not know if the technology that was developed in another location would be perceived in similar ways in different locations. By establishing a cross-cultural validation of a model, this would not only achieve greater validity of the model but also allow meaningful comparisons and analyses between and among samples to be made. This research moves in this direction. In other words, it is futile to facilitate a technology which is implemented in a western country or for specific group of users and then apply it in non-western countries that have substantial cultural differences without taking into consideration the social, organisational, individual and cultural factors. Therefore, policy makers should not consider the strategies related to content, design and structure in one country and simply apply it to another as it will be doomed to fail in other contexts. Additionally, it is recommended that educational authorities should decide on the best approach that fits their students before implementing any new technology. In other words, higher educational institutions should keep investing in technology and focus on decreasing obstacles related to adoption and implementation of technology integration in order to improve their students' learning experience. Additionally, providing a system which promotes ease of use and user-friendliness could play a key role in enhancing learning effectiveness and efficiency. Furthermore, policy makers should provide all facilities for the students to use the system including the necessary hardware and software. They should also emphasise on the importance of such technologies on enhancing the students' QWL.

This study has some limitations. First, we did not integrate the cultural variables within the model and assumed Hofstede's findings to be true. Second, the actual use of the e-learning system was measured using a self-reported questionnaire as it was not practical to capture the actual use of the system through the student log file. Finally, data were collected from students using a convenience sampling technique and thus should not necessarily be considered representative of the population. Therefore, generalisation of these findings should be treated with caution.

\section{References}

Ajzen, I. (1991). The theory of planned behavior. Organizational Behavior and Human Decision Processes, 50, $179-211$.

Ajzen, I. \& Fishbein, M. (1980). Understanding attitudes and predicting social behavior Vol. 278. Englewood Cliffs, NJ: Prentice-Hall.

Arbuckle, J. (2009) Amos 18 User's Guide. SPSS Incorporated.

Bagozzi, R. P. (2007). The legacy of the technology acceptance model and a proposal for a paradigm shift. Journal of the Association for Information Systems, 8, 3, 244-254.

Bandura, A. (1997). Self-efficacy: the exercise of control Vol. 604. New York: W.H. Freeman.

Baroud, F. \& Abouchedid, K. (2010). e-learning in Lebanon: patterns of e-learning development in lebanon's mosaic educational context. In U. Demiray (Ed.), e-learning practices: cases on challenges facing e-learning and national development, institutional studies and practices (pp 409-424). Eskisehir, Turkey: Anadolu University. 
Blackboard Inc. (2012). Accelerate with Blackboard Learn. [online document] Retrieved September 9, 2012, from http://blackboard.com/Platforms/Learn/Products/Blackboard-Learn.aspx

Benbasat, I. \& Barki, H. (2007). Quo vadis, TAM. Journal of the Association for Information Systems, 8, 211-218.

Carmines, E. G. \& McIver, J. P. (1981). Analyzing models with unobserved variables: analysis of covariance structures. Social measurement, 10, 65-115. Current issues.

Carvalho, A., Areal, N. \& Silva, J. (2011). Students' perceptions of blackboard and moodle in a portuguese university. British Journal of Educational Technology, 42, 824-841.

Cascio, W. F. \& McEvoy, G. (2003). Managing human resources: productivity, quality of work life, profits. New York: McGraw-Hill.

Chang, S. C. \& Tung, F. C. (2008). An empirical investigation of students' behavioural intentions to use the online learning course websites. British Journal of Educational Technology, 39, 71-83.

Chau, P. Y. K. \& Hu, P. J. (2002). Examining a model of information technology acceptance by individual professionals: an exploratory study. Journal of management information systems, 18, 191-230.

Chesney, T. (2006). An acceptance model for useful and fun information systems.

Chung, J. E., Park, N., Wang, H., Fulk, J. \& McLaughlin, M. (2010). Age differences in perceptions of online community participation among non-users: an extension of the Technology Acceptance Model. Computers in Human Behavior, 26, 1674-1684.

Clark, R. C. \& Mayer, R. E. (2011). E-learning and the science of instruction: proven guidelines for consumers and designers of multimedia learning. New York: Pfeiffer.

Davis, F. D. (1989). Perceived usefulness, perceived ease of use, and user acceptance of information technology. MIS Quarterly, 13, 319-340.

Davis, F. D., Bagozzi, R. P. \& Warshaw, P. R. (1989). User acceptance of computer technology: a comparison of two theoretical models. Management Science, 982-1003.

DeVellis, R. F. (2003). Scale development: theory and applications. Newbury Park: CA: Sage.

Gefen, D. \& Straub, D. W. (1997). Gender differences in the perception and use of e-mail: an extension to the technology acceptance model. MIS Quarterly, 21, 4, 389-400.

Hair, J. F. J., Black, W. C., Babin, B. J., Anderson, R. E. \& Tatham, R. L. (2010). Multivariate data analysis. New Jersey: Prentice-Hall.

Hofstede, G. \& Hofstede, J. (2005). Cultures and organizations: software of the mind. McGraw-Hill.

Hu, L. \& Bentler, P. M. (1999). Cutoff criteria for fit indexes in covariance structure analysis: conventional criteria versus new alternatives. Structural Equation Modeling: A Multidisciplinary Journal, 6, 1-55.

Iskander, M. (2008). Innovative techniques in instruction technology, E-learning, E-assessment and education. New York, NY: Springer.

King, W. R. \& He, J. (2006). A meta-analysis of the technology acceptance model. Information \& Management, 43, 6, 740-755.

Kline, R. B. (2005). Principles and practice of structural equation modeling. New York, NY: Guilford Press.

Kripanont, N. (2007) Examining a technology acceptance model of internet usage by academics within Thai business schools. Victoria University Melbourne, Australia.

Lewis, W., Agarwal, R. \& Sambamurthy, V. (2003). Sources of influence on beliefs about information technology use: an empirical study of knowledge workers. MIS Quarterly, 27, 4, 657-678.

Li, N. \& Kirkup, G. (2007). Gender and cultural differences in Internet use: a study of China and the UK. Computers \& Education, 48, 301-317.

Liaw, S. \& Huang, H. (2011). A study of investigating learners attitudes toward e-learning.

Liaw, S.-S. (2008). Investigating students' perceived satisfaction, behavioral intention, and effectiveness of e-learning: a case study of the Blackboard system. Computers $\mathcal{E}$ Education, 51, 864-873.

Liu, I. F., Chen, M. C., Sun, Y. S., Wible, D. \& Kuo, C. H. (2010). Extending the TAM model to explore the factors that affect Intention to Use an Online Learning Community. Computers \& Education, 54, $600-610$.

Maldonado, U. P. T., Khan, G. F., Moon, J. \& Rho, J. J. (2009) E-learning motivation, students' acceptance/use of educational portal in developing countries: a case study of Peru. Computer Sciences and Convergence Information Technology, 2009. ICCIT'09. Fourth International Conference on. (pp 1431-1441). IEEE.

McCoy, S., Everard, A. \& Jones, B. (2005). An examination of the technology acceptance model in Uruguay and the U.S.: a focus on culture. Journal of Global Information Technology, 8, 27-45.

McCoy, S., Galletta, D. F. \& King, W. R. (2005). Integrating national culture into IS research: the need for current individual level measures. Communications of the Association for Information Systems, 15, 12, 211-224.

Nasser, R. \& Abouchedid, K. (2000). Attitudes and concerns towards distance education: the case of Lebanon. Online Journal of Distance Learning Administration, 3, 1-10. 
Ngai, E. W. T., Poon, J. K. L. \& Chan, Y. H. C. (2007). Empirical examination of the adoption of WebCT using TAM. Computers \& Education, 48, 250-267.

Park, S. Y. (2009). An analysis of the technology acceptance model in understanding university students' behavioral intention to use e-learning. Educational Technology \& Society, 12, 150-162.

Peng, H., Su, Y. J., Chou, C. \& Tsai, C. C. (2009). Ubiquitous knowledge construction: mobile learning re-defined and a conceptual framework. Innovations in Education and Teaching International, 46, 171-183.

Pituch, K. A. \& Lee, Y. (2006). The influence of system characteristics on e-learning use. Computers $\mathcal{E}$ Education, 47, 222-244.

Robinson, J. P., Wrightsman, L. S. \& Andrews, F. M. (1991) Measures of personality and social psychological attitudes. Academic Pr.

Roca, J. C., Chiu, C. M. \& Martínez, F. J. (2006). Understanding e-learning continuance intention: an extension of the Technology Acceptance Model. International Journal of Human-Computer Studies, 64, 683-696.

Rogers, M. (2003) Diffusion of innovations (5th ed.). New York: Simon and Schuster.

Rodriguez, T. \& Lozano, P. (2011). The acceptance of Moodle technology by business administration students. Computers \& Education, 58, 1085-1093.

Sánchez, R. A. \& Hueros, A. D. (2010). Motivational factors that influence the acceptance of Moodle using TAM. Computers in Human Behavior, 26, 1632-1640.

Saeed, K. A. \& Abdinnour-Helm, S. (2008). Examining the effects of information system characteristics and perceived usefulness on post adoption usage of information systems. Information $\mathcal{E}$ Management, 45, $376-386$.

Sanchez-Franco, M. J. (2010). WebCT-The quasimoderating effect of perceived affective quality on an extending Technology Acceptance Model. Computers \& Education, 54, 37-46.

Schepers, J. \& Wetzels, M. (2007). A meta-analysis of the technology acceptance model: investigating subjective norm and moderation effects. Information \& Management, 44, 90-103.

Sekaran, U. \& Bougie, R. (2011). Research methods for business : a skill building approach (5th ed.). Wiley India Pvt. Ltd.

Srite, M. \& Karahanna, E. (2000) A Cross-Cultural Model of Technology Acceptance. The Annual Diffusion of Innovations Group in Information Technology (DIGIT). Charlotte, NC.

Srite, M. \& Karahanna, E. (2006). The role of espoused national cultural values in technology acceptance. MIS Quarterly, 30, 679-704.

Straub, D. \& Burton-Jones, A. (2007). Veni, vidi, vici: breaking the TAM logjam. Journal of the Association for Information Systems, 8, 223-229.

Straub, D., Keil, M. \& Brenner, W. (1997). Testing the technology acceptance model across cultures: a three country study. Information \& Management, 33, 1-11.

Sun, H. \& Zhang, P. (2006). The role of moderating factors in user technology acceptance. International Journal of Human-Computer Studies, 64, 53-78.

Tarhini, A., Hone, K. \& Liu, X. (2013a) Extending the TAM model to empirically investigate the students' behavioural intention to use e-learning in developing countries. Science and Information Conference (SAI), 2013. (pp 732-737). IEEE.

Tarhini, A., Hone, K. \& Liu, X. (2013b). Factors affecting students' acceptance of e-learning environments in developing countries: a structural equation modeling approach. International Journal of Information and Education Technology, 3, 54-59.

Tarhini, A., Hone, K. \& Liu, X. (2013c). User acceptance towards web-based learning systems: investigating the role of social, organizational and individual factors in european higher education. Procedia Computer Science, 17, 189-197.

Taylor, S. \& Todd, P. (1995). Decomposition and crossover effects in the theory of planned behavior: a study of consumer adoption intentions. International Journal of Research in Marketing, 12, 137155.

Teo, T. (2009a). The impact of subjective norm and facilitating conditions on pre-service teachers' attitude toward computer use: a structural equation modeling of an extended Technology Acceptance Model. Journal of Educational Computing Research, 40, 89-109.

Teo, T. (2009b). Is there an attitude problem? Reconsidering the role of attitude in the TAM. British Journal of Educational Technology, 40, 1139-1141.

Teo, T. (2010). A structural equation modelling of factors influencing student teachers' satisfaction with e-learning. British Journal of Educational Technology, 41, E150-E152.

Teo, T. (2011). Assessing the cross-cultural validity study of the E-learning Acceptance Measure (ElAM): a structural equation modeling approach. International Journal of Educational and Psychological Assessment, $8,43-53$. 
Teo, T. \& Noyes, J. (2011). An assessment of the influence of perceived enjoyment and attitude on the intention to use technology among pre-service teachers: a structural equation modeling approach. Computers \& Education, 57, 1645-1653.

Teo, T., Luan, W. S. \& Sing, C. C. (2008). A cross-cultural examination of the intention to use technology between Singaporean and Malaysian pre-service teachers: an application of the Technology Acceptance Model (TAM). Journal of Educational Technology and Society, 11, 265-280.

UNDP (2002) United nations development program. Arab Human Development Report. New York.

Venkatesh, V. \& Bala, H. (2008). Technology acceptance model 3 and a research agenda on interventions. Decision Sciences, 39, 273-315.

Venkatesh, V. \& Davis, F. D. (2000). A theoretical extension of the technology acceptance model: four longitudinal field studies. Management Science, 46, 186-204.

Venkatesh, V. \& Morris, M. G. (2000). Why don’t men ever stop to ask for directions? Gender, social influence, and their role in technology acceptance and usage behavior. MIS Quarterly, 24, 115-139.

Venkatesh, V., Morris, M. G., Davis, G. B. \& Davis, F. D. (2003). User acceptance of information technology: toward a unified view. MIS Quarterly, 27, 425-478.

Wang, Y. S., Wu, M. C. \& Wang, H. Y. (2009). Investigating the determinants and age and gender differences in the acceptance of mobile learning. British Journal of Educational Technology, 40, 92-118.

Yousafzai, S. Y., Foxall, G. R. \& Pallister, J. G. (2007). Technology acceptance: a meta-analysis of the TAM: part 1. Journal of Modelling in Management, 2, 251-280.

Zakour, A. B. (2004) Cultural differences and information technology acceptance. (pp 156-161).

Zhang, S., Zhao, J. \& Tan, W. (2008). Extending TAM for online learning systems: an intrinsic motivation perspective. Tsinghua Science and Technology, 13, 312-317.

Zikmund, W. (2009). Business research methods. New Haven, CT: Texere Publishing Limited. 